\title{
Therapeutic Communication and Client Counseling: Toward a Conceptual Framework for Strategic Interpersonal Engagement
}

\author{
Ephraim Okoro, PhD \\ Howard University \\ School of Business \\ 2400 Sixth St NW, Washington, DC 20059, USA \\ Patrick Adigwe, PhD \\ Howard University \\ School of Education \\ 2400 Sixth St NW, Washington, DC 20059, USA
}

\begin{abstract}
This study operationalizes strategic communication in the context of counseling environment. It emphasizes the concept of strategic communication as an outgrowth of therapeutic engagement between clients and counselors. It then explains that strategic communication is intended to achieve a counselor's purpose or mission and therapeutic interaction is designed to create an advantageous relationship for the client, which is the focus of counselor-client relationship. In the comparison and contrast of the two communication concepts, the study synthesizes that therapeutic communication utilizes effective verbal and nonverbal behaviors, as well as crosscultural communication competence, to cultivate a relationship that fosters free and open sharing of information and ideas between healthcare professionals and their clients. Studies (Knapp \& Hall, 2002; Duggan, 2006) indicate that clients differ significantly in their backgrounds, race, ethnicity, and nationality; therefore, strategic communication correlates with therapeutic interactive process in which human empathy and relationship building is the focus in client treatment. Fundamentally, this study suggests that counselors' effective use of communicative, strategic, and therapeutic skills in counseling and treatment procedures facilitates the establishment of a trusting and respectful relationship, resulting in a rapid client/patient recovery. Consequently, the overall treatment experience is less stressful for clients, allowing the cultivation of increased trust and dependability on counselors and the treatment process is exceedingly fast. The study then concludes that strategic communication correlates with therapeutic engagement, which is an objective, purposeful, and empathic form of clinical interaction designed to eliminate unnecessary agonizing and time-consuming clients' treatment. Recommendations provided include avoiding non-therapeutic type of communication, such as engaging in personal/intimate discussions, creating argumentative/defensivelaggressive solicitation and response format, and elimination of abrupt change of subject, which discourages a two-way exchange of information.
\end{abstract}

Strategic communication, therapeutic communication, counselor-client relationship, verbal-and nonverbal behavior, cross-cultural competence

\section{Introduction}

Recent studies over the past four decades have acknowledged that effective communication skills are critical to the delivery of high quality counseling, and that they are decisive factors in evaluating and determining the levels of client satisfaction, engagement, and recovery. The unsatisfactory state of clients' state of mind could be effectively analyzed using therapeutic interpersonal communication. A number of psychologists and counselors (Egan, 1975; Ivey \& Authier, 1978, Garnston, 1995) analyzed the struggles and challenges associated with communication competence needed to perform or conduct one-on-one interviews with clients or patients. As a result, some academic institutions are requiring that psychology curricular be expanded to include training and acquisition of fundamental communication skills for efficient and effective interaction or discussion with clients. In their assessment of clients' reactions to treatment, Ivey \& Authier (1978) and Sties, Barkham, Mellor-Clark, \& Connell, 2008) concurred that training programs requiring communication skills and several communicative activities are systematic and structured, designed to enhance interpersonal and inter-cultural communication competence. 
These training programs and skill developments involve the extension of the behavioral repertoire of trainees and their backgrounds. Furthermore, Wright \& Davis (1994) noted that the acquisition of critical communication skills is essential to explain and clarify clients' situations and day-to-day experiences. In order to adequately equip psychology students to perform their counseling and therapeutic functions, fundamental communication skills, such as nonverbal behavior, verbal skills, and different types of listening, are taught in the preliminary phases of psychology and counseling education. The importance of basic communication, therapeutic communication, and/or strategic communication skills to the operational capability in field of psychology could be seen in the enduring or sustainable relationship between counselors and clients, or with other healthcare professionals.

Consistent with the views of other researchers on the impact of communication on clients' level of comfort and response to healing, Egan (1994), Sharply (1997), Minami \& Wampos (2008) concluded that communication is of inestimable value in cultivating interpersonal relationship in a counseling environment, in which a two-way therapeutic or strategic communication skills are needed to improve the rate of recovery of clients from their current state of physical or mental state of minds. Independent of each other, these psychologists stressed that strategic communication skills should be included and taught consecutively or in an appropriate sequence in psychology academic programs. In other words, a rigorous training or orientation in basic communication education and therapeutic skills is required to perform effective counseling services. The speedy recovery or return to normalcy of clients largely depends on the quality of interaction or close engagement with counselors over a period of time. Essentially, fundamental communication skills, therapeutic engagement, and strategic communication elements combined constitute the helping or assisting model identified in Egan's (1994) communication-based model of clients' treatment and recovery. The three phases of the model, according to Mearns \& Thorne (2000), in their "Person-Centered Therapy," included the initial or preliminary problem identification and discussion, gaining and developing new insights, and treatment or healing strategies for sustainability.

\section{Hybrid Approach to Counseling: Strategic Communication and Therapeutic Engagement}

Based on qualitative assessment of psychologists (Hughey, 1974; Harper, Wiens, \& Matarazzo, 1978), therapeutic counseling and other communication-related functions in clients' treatment is dependent on a large measure on the quality of communication in several treatment stages. Clients' reactions and subsequent behaviors is the direct impact of communication effectiveness as well as interpersonal contexts. Both past and recent studies (Cook, 1964; Carkhuff, 1969; Elezi, Tomorri, \& Dobi, 2010) confirmed the perception that the outcome of counseling is the result of skillful management of interpersonal communication competence, including nonverbal behavior during counseling sessions. Furthermore, Esmeralda, Sotiri, \& Lika (2013) contended that independent or group professional practices, such as medicine, pharmacy, psychiatry, psychology, etc., who have engaged in different forms of counseling models, have clearly demonstrated that a client's mental and physical interrelationships should be understood and diagnosed via interpersonal communication in order to successfully achieve sustainable recovery from an unhealthy state of the mind. More than three decades ago, Carkhuff and Bereson (1976), in their assessment of teaching as treatment, supported the clam that the study of individuals has a scientific base, so communication-based method contributed significantly to the mental, behavioral, and emotional wellbeing of clients. Additionally, healthcare administrators and/or professionals, such as social workers, use the hybrid communication models (therapeutic-strategic engagement) to provide social justice, demonstrating empowerment, as well as promoting human dignity, by communicating critical human values. This hybrid strategy of combining effective communication skills and counseling skills make communication competence a critical factor in achieving an immeasurable success in counseling and treatment environments.

\section{Interpersonal Communication Approach in Counseling: Practice and Responsibilities}

One of the primary roles of communication in the counseling environment is the creation, formation, and sustenance of relationships. Northouse \& Northouse (1992) contended that the daily lives of human beings are, to a large extent, established or constructed through verbal and nonverbal interaction. Constant daily interpersonal exchange with clients is the primary channels through which their identity is reshaped and reestablished for developing a healthy interpersonal and group relationship with people in their immediate communities. Emphasizing the role of interpersonal communication, Carkhuff \& Berenson (1976) buttresses that, while the primary objective of counseling remains the need to alleviate personal and interpersonal distress, counselors require an expanded knowledge base, which includes critical awareness of essential values, applicable 
communication strategies, and an understanding of contextual influences, which determines and guides therapeutic plans as well as recovery direction of the healing process.

Specifically, counselors need to be able to assess, comprehend, and harness the counselor-client relationship in order that the client is capable of understanding the process of risk-experimenting with appropriate communicative strategies. Studies (Wright \& Davis, 1994; Sharply, 1997; Mearns \& Thorne, 2000) underscored that effective communication between clients and counselors contributes largely to the outcome of counseling process and creates a sense of security and dependability.

Therefore, it is advisable that counselors adopt strategic or therapeutic techniques in engaging with their clients in order to establish trusting relationship and engagement through constant and open communication. As Sharply (1997) and Mehrabian (1972) noted in their research, an effective counselor needs therapeutic communication skills, since the starting point for the client's learning was traced to his or her own self-understanding. It, therefore, stands to reason that an essential focus in a therapeutic process involves developing and maintaining an interpersonal relationship through constant interaction with clients, thereby dismantling communication difficulties that impede recovery of clients. Based on the preceding study, there is a positive correlation between strategic communication and therapeutic/result-oriented counseling practice.

\section{Contextual Significance of Strategic Communication in Counseling}

In their analysis of therapeutic relationship in cognitive-behavioral therapy, Wright and Davis (1994) evaluated and determined the outcome of patient perceptions and therapist responses. It was then argued that counselors should be aware of concepts and various contexts involving clients' backgrounds and different experiences. Clients and counselors should have the opportunity to discuss, analyze, and assess different situations in order to give the counselor adequate information to make informed evaluation. For instance, a client may be in the middle of a crisis situation, engendered by their previous experience of child abuse, while another client was dealing with the consequences of bad marriage, divorce, or bankruptcy. These clients would be communicating their situations, circumstances, and or distress in a unique jargon or language. Garmston (1995) explained that counselors ought to understand their client's experiences in order to provide appropriate feedback that would address the client's situation clearly. Additionally, an individual may visit a counselor for a critical reason involving his or her child's drug problem or alcohol addiction, and the counselor should be able to comprehend concerns expressed, and then articulate strategic responses that would indicate effective counseling. For assistance, a client with drug or alcohol problem within the context of juvenile addiction should be communicated with, understood, and guided. The important objective in the preceding situations is not necessary delving into the past, but the ability to communicate solutions convincingly in order to deal with the client's present circumstance. Communicating effectively, verbally and nonverbally, in a counseling environment is a major step in getting the needed information as well as in providing remedies for stability and recovery.

\section{Establishing Therapeutic Relationship and Strategic Communicative Process}

In an unpublished doctoral dissertation at the University of Pittsburgh, Hughey (1973) noted the critical importance of counselors and healthcare professionals acquiring skills and competence in several communication phases. This skill set establishes a high level of counseling effectiveness as well as competence to evaluate the dynamics of depression, addiction, power-related issues, sexual abuse, domestic violence, loss and grief, stressful situations, lifestyle changes, unemployment situations, etc. Additionally, Sharply (1997), in a study assessing the use of silence as a technique in counseling procedure, confirmed that nonverbal behavior is of critical value in communicating remedies. The study noted that counselors should possess content knowledge of issues preoccupying the minds of clients in order to provide constructive solution that would improve or stabilize his or her well-being. Therefore, skilled counselors are expected to possess communicative ability to express empathy, emotions, support, and concern for appropriate action in a therapeutic healing context.

\section{Ensuring Communicative Competence and Therapeutic Relationships}

Researchers agreed that the level of therapeutic relationship between clients and counselors differs widely from intimate, professional, and social categories. Therefore, effective counselors are expected to utilize, to a great advantage, his or her appropriate communication skills to harness the quality of counseling and treatment. Understanding the value of a two-way communication in human situations is indispensable to solving or managing human situations. 
In addition to a two-way strategic communication, a sound assessment of individual behaviors, motivation, and interpersonal strengths is required in providing effective counseling. Through interpersonal exchange, counselors and their clients are able to validate areas that need critical exploration in order to improve conditions (Egan, 1994; Mearns \& Thorne, 2000; Norcross, 2011).

Generally speaking, the primary emphasis on interpersonal relationship between clients and counselors is the level of effectiveness based on the evaluation of feelings, experiences, involvements, and ideas. Excellent therapeutic communication skills in counseling and thorough understanding of various stages of mental or physical issues identified in a therapeutic engagement are essential to sustain a reliable client-counselor relationship.

\section{Therapeutic and Non-Therapeutic Communication Techniques}

Studies of recent years agree on the importance of communicating in therapeutic relationship and its effective outcome to the healing process. It has critical implications for clients and therapists in establishing a lasting relationship for the entire duration of treatment. As Wright and Davis (1994) declared that the way in which the exchange between client and therapist is conceptualized or operationalized affects the behavior of therapists and impacts the perception and assessment of clients and their responses. Communication methods of clients may be inappropriate for the method in which clinician conducts treatment and analysis. The expected outcome of counseling is largely depended on adequacy and style of communication between clients and counselors. Indeed, by its nature, counseling is intended or designed to foster relationship between clients and counselors. Consistent with Harper \& Wiens (1978), Garmstorm (1995) observed that counselors' repertoire of competence and skill sets should include contemplating and demonstrating effective communication and change process. Therefore, communicating strategically is an essential or integral component of counseling function or activities. The result of effective counseling relationship depends partly on counselors' ability to express or articulate guidelines and instructions clearly, appropriately, contextually, and strategically. Researchers Balzer (2000) and Duggan (2006) discussing communicating responsibly, repudiated that non-therapeutic styles of interaction were identified as communication methods that do not support a two-way exchange of information. It was strongly suggested that counselors should desist from using non-therapeutic communication strategies because they do not encourage appropriate responses during counseling sessions. Among non-therapeutic communication methods is giving false assurance or reassurance and advancing personal opinions in a counseling situation.

\section{Nonverbal Communication and Counseling: Silence Approach}

In order to achieve an acceptable result in the relationship between counselors and clients, both nonverbal and verbal communication strategies should be used as channels of exchange. Several decades ago, McGowan and colleagues (1962) and Rogers (1942) noted that clients and counselors should engage in a constant communication that involves revealing and interpreting of information via words and symbols. In other words, various forms of human interactions, such as listening, verbal, and nonverbal, should be included in the communication process. Specifically, silence plays a critical role in the counseling environment. Cook (1964) acknowledged that silence is used distinctly to achieve different results in counseling and treatment. These authors operationalized silence as the absence of verbal expression or spoken words. It is conveying information or ideas without verbal utterances. Additionally, Sharply (1997) and Cook (1964) agreed that silence was a shortterm break in verbal expressions between counselors and their clients. Zeligs (1961) had noted that silence, whether in a short-term or long term conversation, it is an effective channel used to convey a significant feedback and to evaluate clients' feelings and reactions in human two-way communication. Based on the preceding research findings, silence is important in strategic and therapeutic communication, and it can be advantageous to clients and counselors in creating meaning or assessing one another's intent or motives.

\section{The Value of Therapeutic Communication in Counseling:}

Other studies (Forchuk, 1993; Knapp \& Hall, 2002; Elezi, Tomorri, Sotiri, \& Dobi, 2012) rationalized that the hallmark of communication is the role it plays in counseling and healing situations in which it uses therapeutic skills focusing on clients' benefits. The authors identified the critical elements of therapeutic communication as non-judgmental approach, empathy, honesty, trust, validation, caring, and the use of active listening techniques. Additionally, in an extended analysis of nurse-client relationship, Sties and colleagues (2008) stated that basic communication is more than exchange of facts and ideas it also constitutes the essence of intimate search to comprehend and analyze human situations, and to create meaning in their verbal or nonverbal expressions. 
Both in nurses-clients relationships as well as in counselors-clients relationships much of the success in the treatment result largely depends on effective and efficient communication. Similarly, nurses and counselors engage in therapeutic communication in order to perform their duties satisfactorily. In the performance of their duties, they assume the role of case managers, educators, and efficient and caring members of health-care professionals. Touch is a strategic channel for communication and is often neglected in the counseling process.

As Balzer (2000) summarized in an analysis of the impact of communicating assertively in a nursing environment, touching has been a major nonverbal channel of communication, and it is utilized effectively to comfort, soothe, as well as establish the rapport needed for therapeutic bonding between healthcare professionals and their clients. As cited by an anonymous source, clients may forget what was said to them, but they may not forget how it made them feel. Essentially, the basic objective of therapeutic and strategic communication is building a trusting and caring interpersonal relationship between clients and counselors using appropriate communication channels. In keeping with each other, researchers agree that the fundamental purpose of communication in counseling is making clients feel cared for, understood, and loved as human beings.

\section{Developing and Sustaining Therapeutic Counselor-Client Relationship:}

While studies (Rogers, 1957; Knapp \& Hall, 2002; Duggan, 2006; ) established a supportive role of communication in counseling, the authors identified specific types of communication needed to facilitate clients/patients recovery stages. Further, Studies by Forchuk (1993) and the assessment of Sties colleagues (2008) validated the use of these communication techniques to encourage clients' free expression of ideas, feelings, and situations in a respectful manner. Several years ago, Norcross (2011) confirmed that the concept of therapeutic communication as a process of healing via communication and relationship building with clients. Minami (2008) concluded that therapeutic communication is a healing formula designed for clients' betterment in various stages of treatment and care giving. In addition, Esmeralda and colleagues (2013) pointed out that strategic interaction is a unique type of client-centered communication that results in ongoing engagement, involving the exchange of information between counselors and clients on different levels of treatment. The strategy has proven successful over the years by employing constant verbal messaging and non-verbal cues through facial expression, tone of voice, eye contact, and other forms of body language to establish focused engagement with client

\section{Barriers to Therapeutic and Strategic Communication}

According to studies (Zeligs, 1961; Wright, 1994; Knapp \& Hall, 2002) determined that communication in many human situations is quite challenging, even under the most ideal situations. Counselors and clients face a range of barriers in their communication with each other; and it is, therefore, important that these barriers are identified in order to maintain a healthy flow of communication with clients. These barriers to effective communication are engendered by client's health status, language, culture, and gender. However, it is critically significant to maintain a consistent evaluation of clients' ability to communicate effectively and clearly by constantly obtaining and reviewing information about clients' psychological, physical, and emotional conditions.

\section{Conclusion and Recommendations}

Effective interpersonal engagement between clients and counselors, between nurses and patients, and between other health-care professionals and clients require a strategic communication in order to achieve the overall goal of healing and counseling. Family members anticipate a speedy recovery process in order that the patient or client could return home on a timely manner. Studies (Mearns \& Thorne, 2000; Ermeralda, Sotiri, \& Lika, 2013) acknowledged that communicating strategically with clients and patients provided acceptable results and that therapeutic communication, which is being used in a limited number of health care facilities in the treatment of patients and clients, should be expanded to many healthcare establishments. The much-needed rapid recovery of patients or clients could be achieved through therapeutic communication, which focuses on the feelings, reactions, and responses of clients/patients at different levels of mental or physical treatment.

Strategic interpersonal communication between clients and counselors based on therapeutic exchange, a form of communication designed to assist physically and mentally disoriented clients and patients. Essentially, skills set needed for therapeutic communication are also useful for cross-cultural environments for the treatment of people from diverse ethnic backgrounds and nationalities. As researchers Wright and associates (1994) and Sherko, Sotiri, \& Lika (2013)) concluded, therapeutic communication is strategic intended to establish numerous objectives for counselors or other healthcare professionals. 
Generally speaking, past and recent studies on counseling and effective healing are consistent in their conclusion that communication plays critical roles human contexts, and it is the exclusive channel for fostering respectful mutual relationships between counselors and clients. Furthermore, efficient and effective therapeutic interaction requires that counselors follow specific rules of privacy and confidentiality to protect the rights of clients and patients during the period of counseling and subsequent treatments.

The rules of privacy include clients' freedom of expression, respect for clients' backgrounds, age, religion, race, ethnicity, and nationality. Finally, the conceptual framework guiding therapeutic communication is grounded in strategic interpersonal communication, cross-cultural communication, and intrapersonal communication. Strategic communication is designed to support and encourage clients' free expression and active interpersonal engagement with counselors during healing and treatment stages. Over time, studies have demonstrated the need to appreciate the critical need of information-sharing and communicative strategies in counseling and treatment. Intrapersonal, interpersonal, group-, and cross-cultural communication is the foundation for therapeutic interaction, in which verbal and nonverbal communicative behaviors play a paramount role. Counselors and other healthcare professionals are encouraged to be mindful of communication barriers, which may impede clients' interactive ability and interpretations, consequently diminish clients' self-esteem and sense of self-worth.

\section{References}

Balzer, R. W. (2000). Communications in nursing: Communicating assertively and responsibly in nursing.

Carkhuff, R.R. \& Berenson, B.G, (1976). Teaching as treatment: an introduction to counseling \& psychotherapy, Amherst, Mass: Human Resources Development Press

Carkhuff, R.R. (1969). Helping and human relations: A primer for lay and professional helpers (Vol. 1), New York Holt: Rinehart \& Winston.

Cook, J. (1964). Silence in Psychotherapy, Journal of Counseling Psychology, 11, pp 42-46.

Duggan, A. (2006). Understanding interpersonal communication process across health contexts: Advances in the last decade and challenges for the next decade, J. Health Communication 11; 93-108

Esmeralda, S., Sotiri, E., \& Lika, E. (2013). Therapeutic Communication. JAHR, Volume 4, Number 7 ,

Egan, G. (1975). The Skilled Helper, a model for systematic and interpersonal relating. Montery, California: Brooks/Cole Publishing Company.

Egan, G. (1994). The Skilled Helper. A problem-Management Approach to helping Pacific Grove, California: Brooks/Cole Publishing Company.

Elezi, F. , Tomorri, S., \& Dobi, F. (2012). Textbook of psychiatry.

Frankel Z.,Levitt, H.M. Murray, D.M., Creenber, L.S. \& Angus, L. (in press). Assessing silent processes in psychotherapy: An empirically-derived categorization system and sampling strategy. Psychotherapy Research.

Forchuk, C. (1993). Interpersonal nursing theory - Notes on nursing theories

Gladstein, G.A. (1974). Nonverbal communication and counseling psychotherapy: A review. Counseling Psychologist, 4(3).

Garmstorm, R. J. (1995). The persuasive art of presenting. The magic of non-verbal communication. Journal of Staff Development, 16, 60-61.

Harper, R.G. Wiens, A.N., Matarazzo, J.D.(1978). Nonverbal communication: The state of the art. New York: Wiley Publishes.

Hughey, A.R. (1974). Nonverbal behaviors, their use in counseling and implications for counselor education (Doctoral dissertation, University of Pittsburgh). Dissertation Abstracts International,35, 189-190 (University Microfilms, No. 74-14, 962.)

Ivey, A.E. \& Authier, J. (1978). Micro-counseling. Innovations in interviewing, counseling, psychotherapy and psycho-education. Springfield: Charles C. Thomas Knapp and Hall (2002). Nonverbal communication in human interaction.

McGowan, J.F. \& Schmidt, L. D. (1962). Counseling: Readings in theory and practice. New analysis. Massachusetts: Addison Wesley.

Mearns D. \& Thorne, B. (2000). Person-Centered Therapy Today, London, Sage.

Mehrabian, A. (1972). Nonverbal communication, Chicgo: Aldine-Atherton. 
Minami, T., \& Wampold, B.E. (2008). Adult psychotherapy in the real world. In W.B. Walsh (Ed.)., Biennial Review of Counseling Psychology (Volume 1, pp. 27-45). New York: Taylor and Francis.

Mohan, T., McGregor, H \& Saunders, S., \& Archer, R. (2007). Communicating!: Theory and Practice $\left(4^{\text {th }}\right.$ Edition), Sydney: Harcourt Brace.

Minami, T., Wampos, B.E. (2008). Adult psychotherapy in the real world. In W.B. Walsh (Ed.)., Biennial Review of Counseling Psychology (Vol. 1., pp. 27-45). New York: Taylor and Francis.

Northouse, P., \& Northouse, 1., (1992). Health communication: Strategies for health professionals.

Norcross, J.C. (Ed.) (2011). Psychotherapy relationships that work ( $2^{\text {nd }}$ ed.).,New York: Oxford University Press.

Rogers, C. (1942). Counseling and Psychotherapy, Boston: Houghton Mifflin Company

Rogers, C.R. (1957). The necessary and sufficient conditions of therapeutic personality change. Journal of consulting psychology, 21, 95-103

Sharply, C. F. (1997). The influence of silence upon client-perceived rapport, Counseling psychology Quarterly, 10, 3, pp. 237-246.

Sties, W. B. Barkham, M. Mellor-Clark, J., \& Connell, J. (2008). Effectiveness of cognitive-behavioral, personcentered and psychodynamic therapies in UK primary-care routine practice: Replication in a larger sample. Psychological Medicine, 38, 677-688.

Tindall R. \& Robinson, (1947). The use of silence as a technique in counseling. Journal of clinical psychology, 3, pp 136-141.

Wright, J. H. \& Davis, D. (1994). The therapeutic relationship in cognitive-behavioral therapy: Patient perceptions and therapist response. Cognitive and behavioral practice, 1, 25-45.

Zeligs, M. (1961). The psychology of silence, Journal of the American Psychoanalytic Association, 9, pp 7-43. 